\title{
Re-examination of the historical range of the greater prairie chicken using provenance data and DNA analysis of museum collections
}

\author{
Jeremy D. Ross ${ }^{1}$, Allan D. Arndt ${ }^{2,4}$, Roger F. C. Smith ${ }^{2}$, Jeff A. Johnson ${ }^{3}$ \& \\ Juan L. Bouzat ${ }^{1, *}$ \\ ${ }^{1}$ Department of Biological Sciences, Bowling Green State University, Bowling Green, OH, 43403-0212, USA; \\ ${ }^{2}$ Department of Zoology, Brandon University, Manitoba, R7A 6A9, Canada; ${ }^{3}$ Museum of Zoology, \\ University of Michigan, Ann Arbor, MI, 48109, USA; ${ }^{4}$ University College of Fraser Valley, Abbotsford, BC, \\ V2S 7M8, Canada (*Corresponding author: Phone: +419-372-9240; Fax: +419-372-2024; E-mail: \\ jbouzat@bgnet.bgsu.edu)
}

Received 7 March 2005; accepted 17 December 2005

Key words: Tympanuchus cupido, range expansion, historical DNA analysis, mitochondrial DNA, mismatch distributions

\begin{abstract}
The extent to which a species has declined within its historical range is commonly used as an important criterion in categorizing the conservation status of wild populations. The greater prairie chicken (Tympanuchus cupido) has been extirpated from much of the area it once inhabited. However, within a large part of this area the species is not considered to be native, warranting no recovery effort or special protection. Demographic analysis based on provenance data from 238 specimens from museum collections in addition to genetic analyses of $100 \mathrm{mtDNA}$ sequences suggest this species was native to the northern prairies, extending from central Minnesota to Alberta, Canada. Provenance data from 1879 to 1935 indicate that $T$. cupido would have required colonization and establishment of populations on an average $11,905 \mathrm{~km}^{2}$ every year, with an estimated per capita growth rate of $8.9 \%$ per year. These rates seem unrealistic given the limited dispersal and high mortality rates reported for this species. A survey of mtDNA sequences from "original" and "expanded" ranges revealed no differences in levels of sequence diversity within ranges $(\pi=0.018 ; \mathrm{SE}=0.004)$ but significant levels of genetic differentiation $\left(F_{\mathrm{ST}}=0.034 ; P=0.013\right)$, which suggest that these populations have been relatively isolated for significant evolutionary time periods. DNA mismatch distributions fit a sudden expansion model consistent with a post-Pleistocene expansion of the species, which coincides with the expansion of prairies into the Canadian plains about 9000 years before present. This study demonstrates the value of museum collections as stores of ecological and genetic information fundamental for the conservation of natural populations, and suggests that the current status of the greater prairie chicken should be re-evaluated within all areas where this species may occur, but is now considered non-native.
\end{abstract}

\section{Introduction}

Effective conservation and restoration strategies for declining populations require accurate information about the historical distribution of species. In addition to actual or projected population size, the extent to which a species' distribution has declined relative to historical levels is commonly used as an important criterion in categorizing the status of a population as critically endangered, endangered or vulnerable (IUCN 2001). Knowledge of a species' historical distribution may be gained through written accounts of species presence by early explorers and naturalists (e.g., 
Douglas 1829; Hind 1860; Coues 1874), long-term studies on the distribution and abundance of natural populations (Collins 2001), evaluation of the fossil record (Lieberman 2000), or through examination of provenance data from museum specimens (Shaffer et al. 1998). Yet, there are limitations to each approach. Historical accounts and fossil records may be fragmentary, provenance data from museum collections are restricted to areas surveyed by early collectors, and longterm studies provide no information prior to human settlement.

Genetic analyses of both contemporary populations and museum (i.e., historic) specimens have proven useful in evaluating past demographic and genetic processes. For example, such studies have provided insight into historical human migrations and trade routes (e.g., Rogers 1995; Arndt et al. 2003), microevolution of natural populations (Lambert et al. 2002; Pergams et al. 2003), postPleistocene colonizations (e.g., Lessa et al. 2003; Rowe et al. 2004), and the temporal loss of genetic diversity in threatened species (e.g., Bouzat et al. 1998; Bouzat 2001; Johnson et al. 2004).

In this study, we used provenance and genetic data from museum specimens to re-examine the historical range of the greater prairie chicken, Tympanuchus cupido pinnatus. This species has been known to occur in grassland habitat from eastern Ontario west to central Alberta in Canada, and south to the Texas-Louisiana border of the USA (Johnsgard 1983). However, its current distribution is restricted to eleven US states. Abundance estimates suggest that only four states contain populations larger than 5000 breeding birds (Kansas - KS, Nebraska - NE, South Dakota - SD, and Colorado - CO) while populations in the other seven states (North Dakota - ND, Minnesota - MN, Wisconsin - WI, Illinois - IL, Missouri - MO, Iowa - IA, and Oklahoma-OK) are greatly reduced (Svedarsky et al. 1999a). Limited abundance, restricted distribution and declining trends of greater prairie chicken populations in many of the US states have resulted in listing this species as endangered (IL, MO, IA), threatened (ND and WI), or of special concern (MN) (see Svedarsky et al. 1999a for a complete synopsis of T. cupido status in USA).

Clearly, the greater prairie chicken has been extirpated from much of the area it once inhabited. However, within a large part of this area (e.g.,
Minnesota, North Dakota and the central Canadian plains) this species is not considered to be native and thus, no recovery effort or special protection is warranted within these regions (Hjertaas et al. 1993). The non-native classification of T. cupido in Canada and north-central USA is based largely upon what we term the "following the plough" (FTP) hypothesis. Based mainly on anecdotal evidence from early naturalists (Coues 1874; Cooke 1888; Roberts 1932), this hypothesis suggests that $T$. cupido expanded its prehistoric range in response to habitat alteration by European settlers. Development of the west during the late 1800 s through early 1900 s is thought to have provided favorable conditions for a rapid range expansion of the greater prairie chicken (Coues 1874). Originating from core populations on the prairies of mid-western USA, the species is believed to have colonized the north-central US states (i.e., Minnesota and North Dakota) and, subsequently, the Canadian prairie provinces of Manitoba, Saskatchewan and Alberta (Figure 1). Under the FTP hypothesis the total area within which T. cupido occurred at some point in the past may, therefore, be divided into "original" and "expanded" ranges, the latter believed to be inhabited only as the direct consequence of human activities, specifically modern agricultural expansion across the prairies (Figure 1).

The earliest suggestion that greater prairie chickens expanded their range following the plough can be traced back to Trippe (1871) and Coues (1874), the latter stating that this species had only reached Fort Randall (at the Nebraska-South Dakota border) by the early 1870's. However, this claim contradicts John James Audubon's earlier reports indicating the presence of T. cupido in the "Big Bend" region of the Missouri River by the 1840's (Audubon 1960). Other 19th century reports from early naturalists also suggest that greater prairie chickens inhabited the Canadian prairies prior to agricultural development by European settlers. For example, during August 1827 David Douglas noted greater prairie chickens on Manitoba prairies north of the 49th parallel (Douglas 1829; see Houston 2002 for possible revision of locale), William Ross King (1866) indicated that the species was abundant in the Assiniboine river valley of Manitoba/Saskatchewan, and Henry Youle Hind (1860) reported multiple sightings of greater 


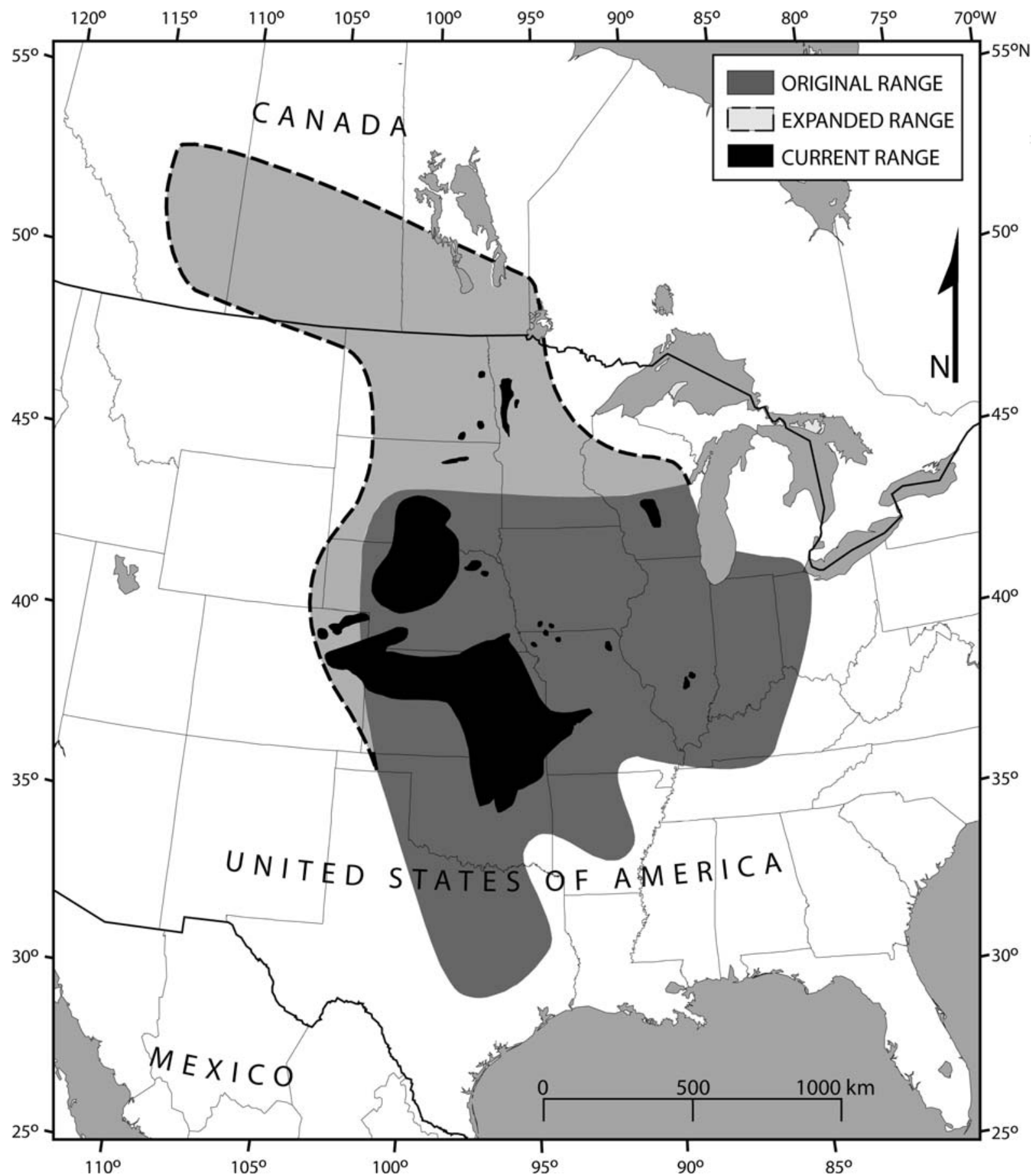

Figure 1. Historical (in gray) and current (in black) distribution range of the greater prairie chicken, Tympanuchus cupido. "Original" and "Expanded" ranges are defined based on the "following the plough" hypothesis (see text). Current distribution adapted from Svedarsky et al. (1999a).

prairie chickens up to $52^{\circ} \mathrm{N}$ latitude in 1857 . All three authors' descriptions of morphology or mating behaviors seem indicative of T. cupido, and as such cast doubt on the idea that greater prairie chickens expanded their range following the plough. 
Such early historical accounts (Douglas 1829; Hind 1860; King 1866), along with the availability of prairie habitat in North Dakota and Canada well before European settlement, lend support to an alternative hypothesis; i.e., that the greater prairie chicken was native to the central plains of Canada, inhabiting tall and mixed-grass prairie ecosystems long before agricultural development. Even with conflicting accounts regarding the presence of greater prairie chicken on the Canadian prairies, the FTP hypothesis has been generally accepted despite limited evidence either for or against it.

In addition to the hypothesized northwestward expansion of T. cupido, a second expansion to the northeast has been suggested as a result of forest clear-cutting in parts of Minnesota, Wisconsin, Michigan and Ontario (Svedarsky et al. 1999a). We have not examined this expansion as this area historically encompassed forest-dominated ecosystems, which do not represent greater prairie chicken habitat.

To evaluate the "following the plough" (FTP) hypothesis, we used provenance and genetic data from $T$. cupido museum specimens. Compiled provenance data allowed us to quantify the historical presence of T. cupido at different times and locations during the assumed range expansion. Using a geographic information system approach, we were able to estimate the average expansion rates necessary to support the rapid colonization proposed by the FTP hypothesis. In addition, genetic analysis of 100 greater prairie chicken samples from the "original" and "expanded" ranges allowed us to evaluate expectations from the FTP hypothesis regarding levels of genetic variation within and between population ranges, as well as potential geographic structuring. Furthermore, DNA mismatch distributions provided insight into past demographic events associated with the species' range expansion over evolutionary time. The present study demonstrates the importance of museum collections for examining species' historical ranges and past demographic events that have direct implications for the conservation of species.

\section{Methods}

Survey and sampling of museum collections

Ornithological collections from natural history museums across North America (see acknowl- edgements) were surveyed for $T$. cupido specimens. We identified specimens collected throughout the putative "expanded" range, including specimens from North Dakota and western Canada. In addition, we incorporated provenance data from egg sets previously surveyed by Houston (2002). We also documented the presence of greater prairie chickens in this area from publications by early naturalists and wildlife managers, indicating year and location of capture/sightings (Kirsch and Kruse 1972; Kobriger 1999; Houston 2002). Tissue samples (feather roots or skin) for genetic analysis were obtained from 111 museum specimens collected across the "original" and "expanded" ranges. In some cases, specimens from museum collections were sampled and mailed to us by their respective museum scientific staff. An additional 29 blood samples from contemporary populations were also included to broaden the representation of samples from the entire greater prairie chicken range.

\section{Estimating rates of expansion}

Provenance data from 154 birds and 84 egg sets collected prior to 1935 were used to analyze the putative expansion rate required under the FTP hypothesis. For each specimen, latitude and longitude values associated with its procurement location, gathered directly from museum specimens' collection tags, were obtained from the Canadian Geographical Names Data Base (http:// www.geonames.nrcan.gc.ca) and the Geographic Names Information System (http://www.geonames.usgs.gov). Specimen locations were then mapped using ArcView GIS, version 3.2 (Environmental Systems Research Institute, Redlands, CA) and further classified by date of collection (Figure 2).

To estimate the rate of range expansion we defined minimum convex polygons (MCPs) using the Animal Movement Extension (Hooge and Eichenlaub 2000) implemented within ArcView, which determined the minimum area for which we had documented presence of $T$. cupido at a particular time period (Figure 2). These areas were characterized strictly on provenance data from clearly identified museum specimens (238 samples). MCPs for the hypothesized expansion were defined by the outermost sample locations for each 5 -year interval from $1879 / 1880$ to 1935 . The 


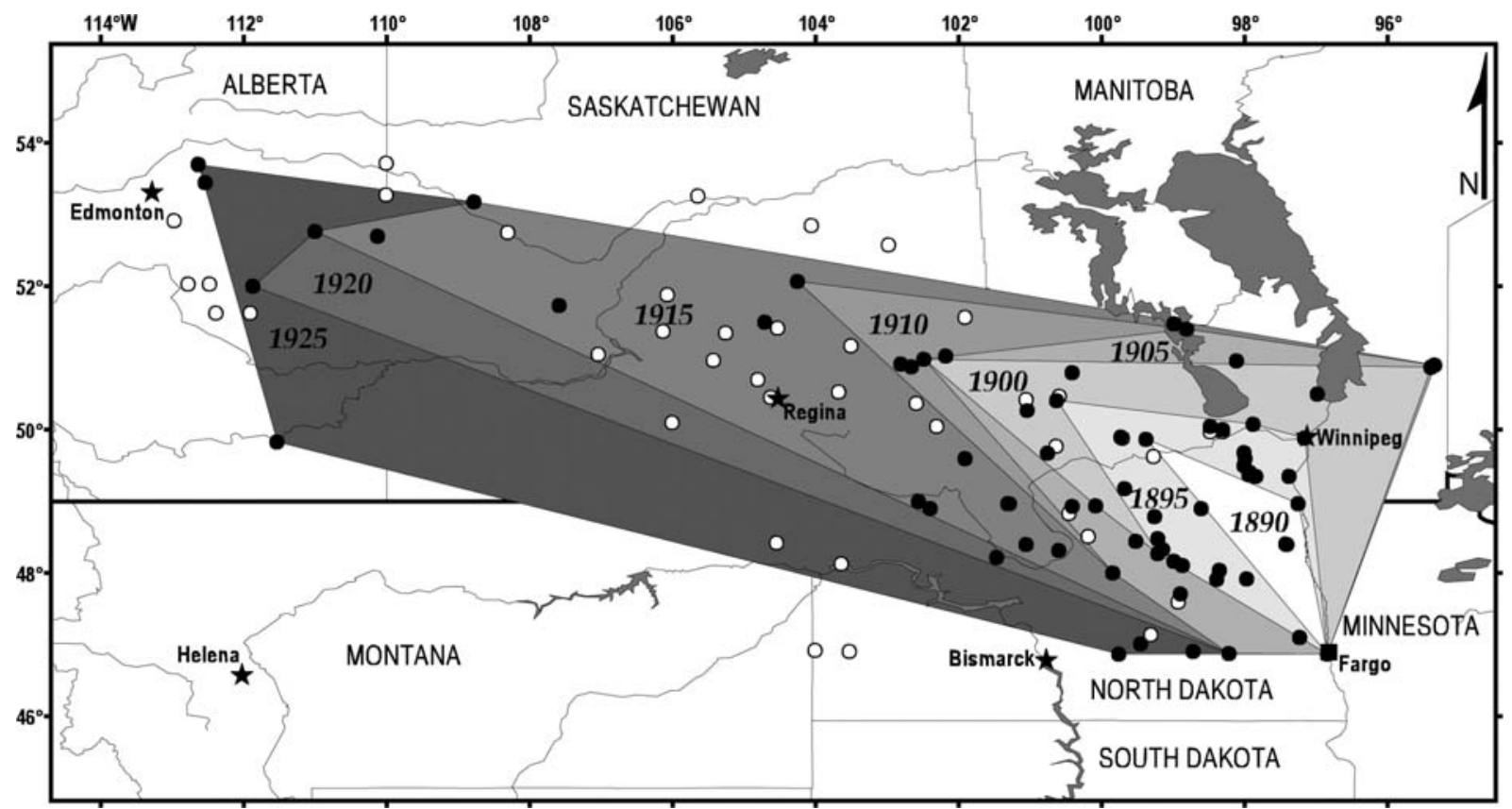

Figure 2. Geographic representation of the putative greater prairie chicken expansion and colonization into North Dakota and Canada. Minimum convex polygons (MCPs) were defined using provenance data from museum specimens collected between 1879 and 1935 (see text). Solid dots represent all locations where museum specimens/egg sets were collected prior to 1925. Open dots represent greater prairie chicken presence prior to 1925 as obtained from historical records.

"starting point" of the expansion (Fargo, ND) was selected based upon postulates of the FTP hypothesis for the greater prairie chicken expansion into North Dakota and Canada (Cooke 1888; Roberts 1932).

The average rate of range expansion was estimated following Okubo (1988) by plotting the progress of the equivalent radial expansion (i.e., the square root of the area divided by the square root of the mathematical $\pi$ ) over time. A regression analysis was performed to test for a linear relationship indicating a constant rate of expansion. This analysis provides an estimate of the average expansion rate required to colonize a given range over a selected time period. Due to the scarcity of museum samples for defining some MCPs, written accounts and reports of $T$. cupido presence prior to 1925 (open dots in Figure 2) were also mapped alongside museum specimens. These points helped determine if the MCP boundaries potentially overestimated the area colonized (e.g., by including areas where the species has never occurred). The rate of population increase $(r)$ associated with the putative range expansion was calculated based on an exponential population growth model and a minimum density value of 1.19 birds $/ \mathrm{km}^{2}$ reported from extant populations (Applegate and Horak 1999; Kobriger 1999).

\section{DNA amplifications and sequencing}

We selected $100 T$. cupido DNA samples for sequence analysis of $214 \mathrm{bp}$ of the mtDNA control region. Sampling was designed to provide widespread coverage of both the "original" and "expanded" ranges and to keep sample sizes even (50 samples each). Samples from the "original" range included eight published sequences (Drovetski 2002; Johnson et al. 2003), 21 museum specimens, and 21 samples from contemporary populations. The "expanded" range was represented by four previously reported sequences (Johnson et al. 2003), 38 museum specimens, and 8 samples from contemporary populations.

DNA extractions from museum specimens were performed by proteinase-K digestion (overnight at $\left.56{ }^{\circ} \mathrm{C}\right)$ in a cell lysis buffer $(10 \mathrm{mM}$ Tris, $100 \mathrm{mM}$ EDTA, 2\% SDS), followed by a standard 
phenol-chloroform extraction and subsequent ethanol precipitation (modified from Sambrook et al. 1989). Concentrations of DNA extracts were standardized at $15-30 \mathrm{ng} / \mu \mathrm{l}$ for further DNA amplification. Two different primer sets were used to amplify the hypervariable region I (HVRI) of the mitochondrial control region. The first set was designed using conspecific sequences published by Lucchini et al. (2001) to amplify a 214 bp section of the HVRI. Primer sequences were as follows: TCCR-F, 5'-CACATACATTATGGTACCGG-3'; TCCR-R, 5'-CAATAAATCCATCTGGTACG-3'. The second set included primers 16775L (Quinn 1992) and 521H (Quinn and Wilson 1993) with nested primers as described in Johnson and Dunn (2006). The second set of primers amplified $384 \mathrm{bp}$ of the mtDNA control region, fully overlapping the $214 \mathrm{bp}$ fragment amplified by the TCCR primer set.

Amplification reactions were performed in 25$50 \mu \mathrm{l}$ reaction volumes containing about $50 \mathrm{ng}$ of total DNA as template, $0.2-0.5 \mu \mathrm{M}$ of each primer, $1.25-1.5 \mathrm{mM} \mathrm{MgCl}_{2}, 0.1-0.4 \mathrm{mM}$ dNTPs, and 1-2 U Taq DNA polymerase depending upon the primer set used. Amplification profiles included a denaturing step at $94^{\circ} \mathrm{C}$ for $3 \mathrm{~min}$, followed by 35 cycles of $30 \mathrm{~s}$ at $94{ }^{\circ} \mathrm{C}, 30 \mathrm{~s}$ at $48{ }^{\circ} \mathrm{C}$, and $45 \mathrm{~s}$ at $72{ }^{\circ} \mathrm{C}$, with a final extension step at $75{ }^{\circ} \mathrm{C}$ for $10 \mathrm{~min}$. In some cases a second round of amplification was necessary to obtain suitable amounts of product from historical samples. Extreme caution was exercised to prevent contamination of DNA extractions and amplification reactions with conspecific DNA. All DNA extractions and amplification reactions of museum specimens were performed in different lab facilities or at different times from similar procedures on contemporary samples. Blank controls were performed for most DNA extractions of historical samples (i.e., extraction protocols were performed without samples and subsequently subjected to PCR to test for possible contamination). Reactions were prepared using high recovery filtered pipette tips to prevent aerosol contamination. Negative controls were consistently used to monitor potential contamination during PCR amplifications.

Twenty-nine samples from contemporary populations and 59 samples from museum specimens were amplified and directly sequenced, both forward and reverse, using the amplification primers previously described. DNA sequencing reactions were performed using either a BigDye Terminator Cycle Sequencing Kit (Applied Biosystems, Foster City, CA) or a CEQ Dye Terminator Cycle Sequencing Kit (Beckman Coulter, Fullerton,CA) and analyzed in an ABI 310 (Applied Biosystems) or a CEQ 8000 (Beckman Coulter) capillary DNA sequencer, respectively. Electrophoretograms were visually inspected to ensure proper base calling. Amplification products from 17 museum specimens did not produce quality sequences through direct sequencing and, thus, were cloned using a TOPO TA cloning kit (Invitrogen Corporation, Carlsbad, CA). Positive clones were purified using the QIAprep Spin Miniprep Kit (QIAGEN Inc., Valencia, CA) for subsequent DNA sequencing. To confirm the reliability of these sequences, at least two independent clones were sequenced. Additional sequencing was conducted to resolve any discrepancies between independent sequencing reactions from the same sample. Confirmation of these sequences (three samples) was based upon the detection of two identical sequences from independent clones. Previously unpublished DNA sequences used in this study are deposited in GenBank (accession numbers: AY855226AY855262).

\section{Genetic analyses}

HVRI mtDNA sequences were trimmed to the 214 bp section located between the TCCR-F and TCCR-R amplification primers, and aligned using Clustal X multiple sequence alignment software (Thompson et al. 1997). DNA sequences were analyzed using the programs MEGA (Molecular Evolutionary Genetic Analysis) version 2.1 (Kumar et al. 2001) and DnaSP version 4.00.6 (Rozas and Rozas 1999). Specimens were grouped as either "original" or "expanded" according to their hypothesized historical status (i.e., located in the putative original or expanded ranges). Standard estimates of genetic diversity (raw and net sequence divergence, haplotype diversity $\mathrm{Hd}$, and nucleotide diversity $\pi$; Nei and Kumar 2000) and their corresponding standard errors (estimated using a bootstrap method with 500 replications; Kumar et al. 2001) were calculated for each group as well as for the total population sample. An estimate of mean interpopulation sequence 
diversity is given by $\delta_{\mathrm{ST}}=\pi_{\mathrm{T}}-\pi_{\mathrm{S}}$, where $\pi_{\mathrm{T}}$ and $\pi_{\mathrm{S}}$ represent the mean sequence diversity for the entire population and the subpopulations, respectively. MODELTEST (Posada and Crandall 1998) was used to determine the best model of sequence evolution inferred from the data (transversional model $\mathrm{TVM}+\mathrm{G}$, based on Akaike Information Criterion). Estimates of genetic diversity and subsequent analyses did not change significantly by the distance methods used, which included the number of pairwise differences, the proportion of differences $\left(P_{\mathrm{i}}\right)$, the Kimura-2 parameter and Tamura-Nei models, and the best model inferred from MODELTEST. Therefore, we only report results on the absolute number and the proportion of pairwise differences among sequences.

An analysis of molecular variance (AMOVA; Schneider et al. 2000) was performed to estimate levels of genetic differentiation $\left(F_{\mathrm{ST}}\right)$ between samples from the "original" and "expanded" ranges. Significance levels for variance components were computed in ARLEQUIN using a non-parametric procedure with 1000 random permutations (Schneider et al. 2000).

ARLEQUIN was also used to develop a minimum spanning haplotype network and DNA mismatch distributions, both based upon pairwise distances among sequences. The mismatch distributions were tested for goodness of fit to Rogers and Harpending's (1992) sudden expansion model, which assumes that populations at demographic equilibrium will display a multimodal distribution of pairwise differences, whereas populations that experienced a sudden demographic expansion will show a unimodal mismatch distribution. This approach was not used to test the FTP hypothesis, but instead to evaluate the evolutionary range expansion of this species. The validity of the sudden expansion model is tested using a parametric bootstrap approach where 500 random samples are generated using a coalescent algorithm in accordance with the inferred demographic expansion (Schneider et al. 2000). $P$-values are then calculated as the proportion of simulations producing a larger sum-of-squared deviation (SSD) than the observed SSD. From the mismatch distribution, ARLEQUIN provides an estimator of the age of expansion $(\tau)$ that best fits the data as well as confidence intervals generated through the same parametric bootstrap approach described above (Schneider et al. 2000). Using simulations, Schneider and Excoffier (1999) demonstrated that, although estimates of demographic parameters such as population sizes $\left(\theta_{0}\right.$ and $\left.\theta_{1}\right)$ may not be reliable, the expansion time is estimated without much bias and with reasonable precision. From the mismatch distribution, the proportion of the times the true value of $\tau$ is outside the empirical confidence intervals is approximately equal to the significance level $\alpha$ (Schneider and Excoffier 1999). An estimate of the absolute time since expansion was then calculated using the equation $\tau=2 u t$, where $t$ is the number of years since genetic coalescence, and $u$ is the mutation rate for the whole haplotype (Rogers and Harpending 1992; Schneider et al. 2000). Rogers (1992, 1995) has shown that the estimate of $\tau$ is relatively insensitive to violations of assumptions from the sudden expansion model, constant mutation rate across nucleotide sites, and no population subdivision.

\section{Results}

\section{Rates of range expansion}

Surveys of 27 museum collections throughout the USA and Canada, plus the Natural History $\mathrm{Mu}-$ seum in London, provided provenance data for 238 greater prairie chicken specimens/egg sets collected from North Dakota and Canada between 1879 and 1935. The mapped distribution of these samples indicated that, prior to $1925, T$. cupido range extended, at least, to the northern limits of the mixed-grass prairies of Canada, encompassing an estimated area of approximately $550,000 \mathrm{~km}^{2}$ (Figure 2). This is consistent with reports of greater prairie chicken presence throughout that region during the same time period (Houston 2002).

Provenance data from the museum specimens allowed the characterization of eight MCPs during the hypothesized expansion from 1879 to 1935 (Figure 2). The presence of only one sample point between 1879 and 1885 prevented the construction of an MCP for that time interval. In addition, museum specimens collected after 1925 did not cause MCPs to increase in size, thus 1925 was considered the end of the expansion period. The 


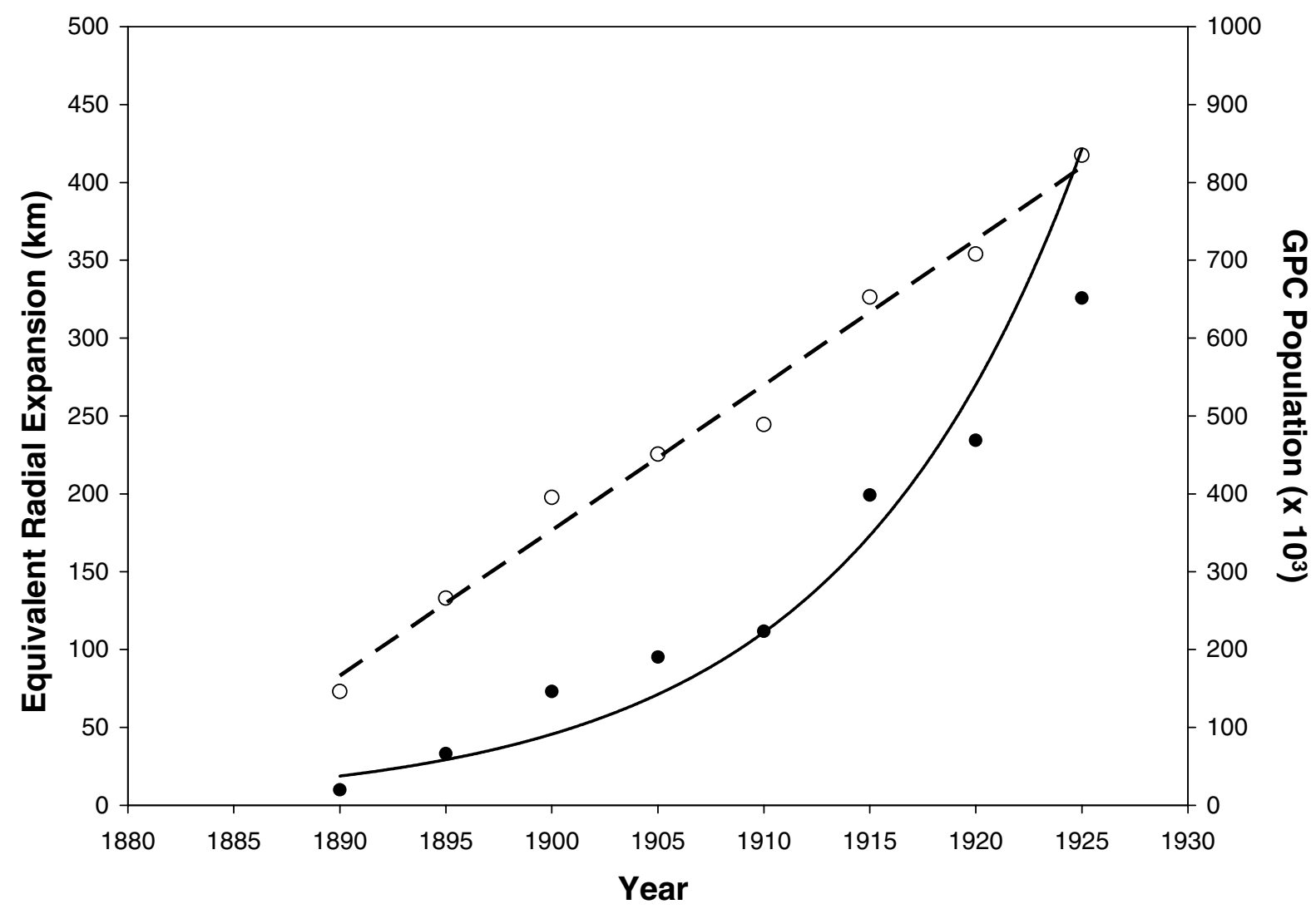

Figure 3. Range radius expansion (open dots) and abundance estimates (solid dots) over time during the putative greater prairie chicken invasion into North Dakota and Canada. Dotted and solid lines represent the linear regression $\left(R^{2}=0.984, P<0.001\right)$ and exponential function $\left(R^{2}=0.910, P<0.001\right)$ that best fit the assumed range expansion and population growth, respectively.

sequential increase of MCP area over time corresponded to an equivalent radial expansion that fit a linear regression $\left(R^{2}=0.984, \quad P<0.001\right.$; Figure 3), indicating a constant radial spread of $9.3 \mathrm{~km} /$ year. Overall, the establishment of greater prairie chicken populations following the plough would have required an average colonization rate of $11,905 \mathrm{~km}^{2} /$ year over the 46-year period under consideration. Assuming a constant density of 1.19 birds $/ \mathrm{km}^{2}$ (i.e., a low density estimate from extant populations) in each MCP, abundance estimates plotted against time fit an exponential growth model $\left(R^{2}=0.910, P<0.001\right.$, Figure 3$)$ with an average growth rate $(r)$ of 0.089 . When MCPs were constructed using additional presence data from historical reports, the estimated equivalent rate of radial expansion $(9.6 \mathrm{~km} /$ year$)$ was slightly higher than that calculated from museum specimens, thus requiring a higher growth rate over the same time period.

\section{Genetic analyses}

The DNA sequence analysis of the mtDNA HVRI from 100 samples, including samples from museum and contemporary specimens, revealed 45 distinct mitochondrial haplotypes with 34 polymorphic sites. Total haplotype diversity was 0.963 ( $\mathrm{SE}<0.001)$. Sequence diversity $(\pi)$ for the entire population sample was $3.968(\mathrm{SE}=0.963)$ and $0.017(\mathrm{SE}=0.004)$ for the absolute number and the proportion of nucleotide differences, respectively (Table 1 ). When samples were grouped into "original" and "expanded" populations, we did not find significant differences in their levels of genetic diversity, as indicated by the similar levels of haplotype diversity in the original $(\mathrm{Hd}=0.949 ; \mathrm{SE}=0.002)$ and expanded $(\mathrm{Hd}=0.972 ; \mathrm{SE}=0.001)$ ranges, the low levels of net sequence divergence between the two groups (less than 1\% difference; Table 1), and the low 
Table 1. Estimates of genetic diversity (raw and net sequence divergence, and nucleotide diversity $\pi$ ) within and between greater prairie chicken populations from the "original" and "expanded" ranges, and for the entire population sample. Standard errors in parentheses were calculated using the bootstrap method implemented in MEGA (Kumar et al. 2001)

\begin{tabular}{|c|c|c|}
\hline & $\begin{array}{l}\text { Number of } \\
\text { differences }\end{array}$ & $\begin{array}{l}\text { Proportion of } \\
\text { differences }\left(P_{\mathrm{i}}\right)\end{array}$ \\
\hline \multicolumn{3}{|l|}{ Raw and net divergence } \\
\hline \multicolumn{3}{|l|}{ Within groups } \\
\hline Expanded & $3.989(0.866)$ & $0.019(0.004)$ \\
\hline Original & $3.813(0.911)$ & $0.018(0.004)$ \\
\hline Between groups & $4.034(0.957)$ & $0.019(0.004)$ \\
\hline Net between groups & $0.133(0.115)$ & $0.001(0.001)$ \\
\hline \multicolumn{3}{|l|}{ Sequence diversity $(\pi)$} \\
\hline Within groups & $3.901(0.911)$ & $0.018(0.004)$ \\
\hline Entire population & $3.968(0.963)$ & $0.017(0.004)$ \\
\hline Interpopulation diversity & $0.067(0.053)$ & $<0.001(<0.001)$ \\
\hline
\end{tabular}

interpopulation sequence diversity. Overall, average sequence diversity within ranges was not significantly different than that detected between ranges (Table 1).

The AMOVA indicated significant levels of genetic differentiation $\left(F_{\mathrm{ST}}=0.033 ; P=0.013\right)$ between samples from the "original" and "expanded" ranges, with $3.3 \%$ of the observed variation explained by differences between ranges. To evaluate potential confounding effects due to temporal differences in sample provenance and potential misassignment of samples to the expanded range, we also performed the analysis including only museum samples from the original range $(n=21)$ and a group of historical samples restricted to Alberta and Saskatchewan (i.e., at the western edge of the putative expanded range; $\mathrm{n}=10)$. This analysis resulted in similar levels of within-group variation $\left(P_{\mathrm{i}}=0.0185\right.$ and $P_{\mathrm{i}}=0.0176$ for the original and the Alberta/Saskatchewan groups, respectively). In addition, it showed higher levels of genetic differentiation $\left(F_{\mathrm{ST}}=0.063\right)$, though the limited sample size may have reduced the power to detect statistical significance $(P=0.074)$.

The minimum spanning network did not reveal an evident geographic association among mitochondrial haplotypes. However, we did find a number of haplotypes that were unique to either the "original" (14 haplotypes) or "expanded" (20 haplotypes) populations (Figure 4). Haplotypes shared among the "original" and "expanded" ranges (11 haplotypes) included the four most abundant haplotypes, accounting for $11,10,8$ and $7 \%$ of the samples, respectively (Figure 4 ).

Mismatch distributions for the "original" and "expanded" populations, as well as for the total population are shown in Figure 5. In all cases, mismatch distributions were not significantly different from those expected under a sudden expansion model that suggested population expansion during the late Pleistocene. The mismatch distribution for the "expanded" population resulted in an estimated $\tau$ value of 2.384 (95\% CI $=1.006-4.839 ; \quad P=0.742 ; \quad$ Figure 5a). Assuming a mutation rate of 0.7 substitutions/ site/million years (s/s/Myr) for the mtDNA HVRI (based on recent estimates from ancient DNA analyses; Lambert et al. 2002), the given $\tau$ places the demographic increase of the "expanded" group at approximately 8000 years before present (ybp), which coincides with the end of the Pleistocene glaciations. Phylogeneticbased estimates of avian HVRI mutation rates are considerably lower (e.g., $0.2 \mathrm{~s} / \mathrm{s} / \mathrm{Myr}$; Avise and Walker 1998) and thus, would infer an expansion prior to the last glacial maximum about 18,000 years ago.

Compared to the mismatch distribution for the "expanded" range, the distribution from the "original" range resulted in a greater $\tau$ value (2.863; 95\% CI $=1.296-7.323 ; P=0.730)$. Using the same mutation rate of $0.7 \mathrm{~s} / \mathrm{s} / \mathrm{Myr}$, this $\tau$ value traces the population expansion signal back $9500 \mathrm{ybp}$. Since the observed distributions in the number of pairwise differences from the 


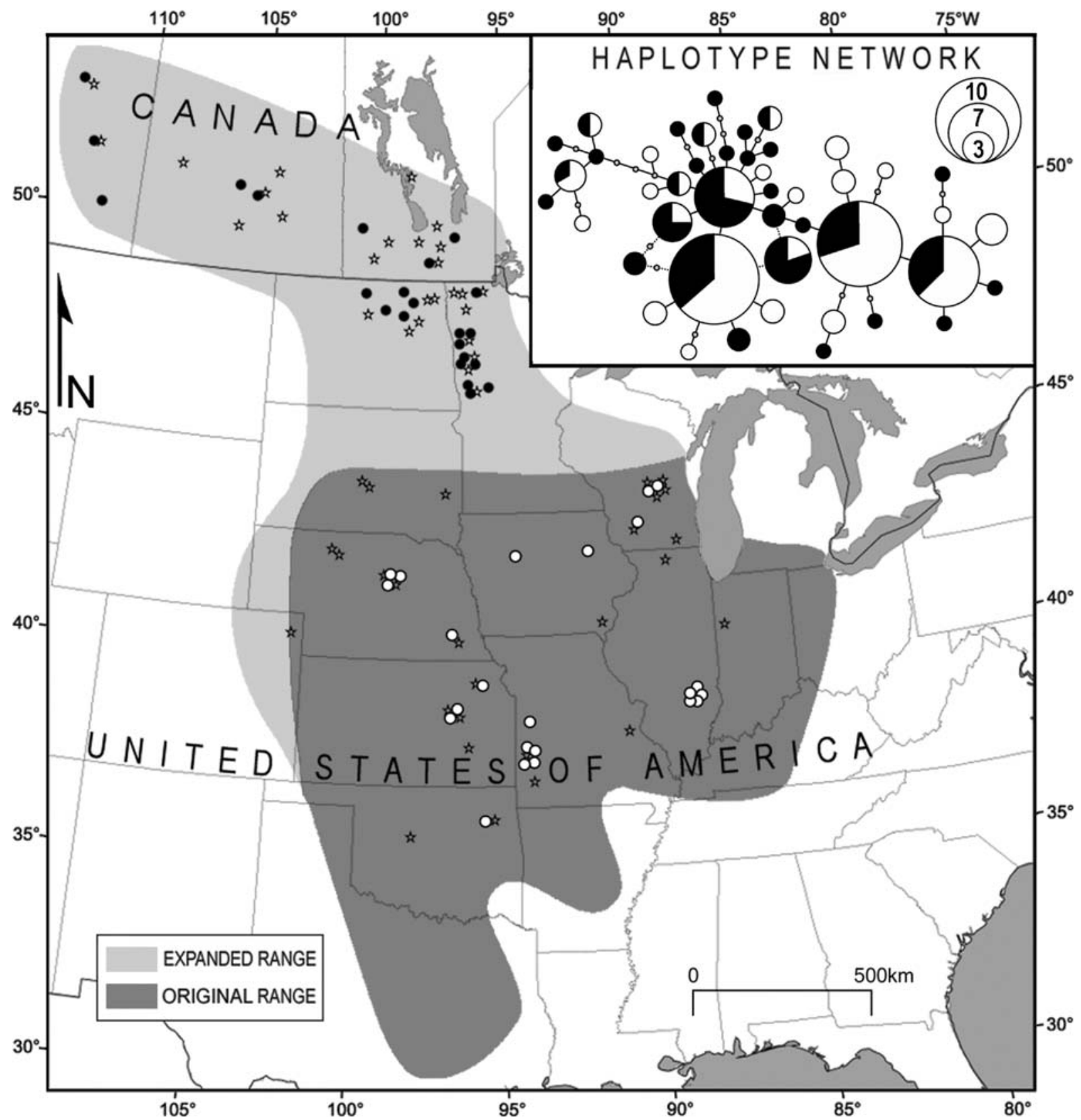

Figure 4. Geographic distribution of T. cupido haplotypes. On the map, white and black dots represent haplotypes unique to the "original" and "expanded ranges," respectively; stars indicate haplotypes that were found in both ranges. In the haplotype network the area of the circles is proportional to the haplotype frequency; the scale shows relative areas for 3, 7, and 10 haplotypes; white and black areas within each circle represent the relative frequency of individuals from the "original" and "expanded" ranges, respectively; small dots represent intermediate haplotypes not found in our study.

"original" and "expanded" populations did not differ significantly (Figure 5a), the data were pooled to examine the species-wide expansion pattern. When considering all samples, the ob- served mismatch distribution (Figure 5b) fit a sudden expansion with a coalescent time at about 9000 ybp $(\tau=2.620 ; 95 \% \mathrm{CI}=1.500-6.221$; $P=0.756)$. 

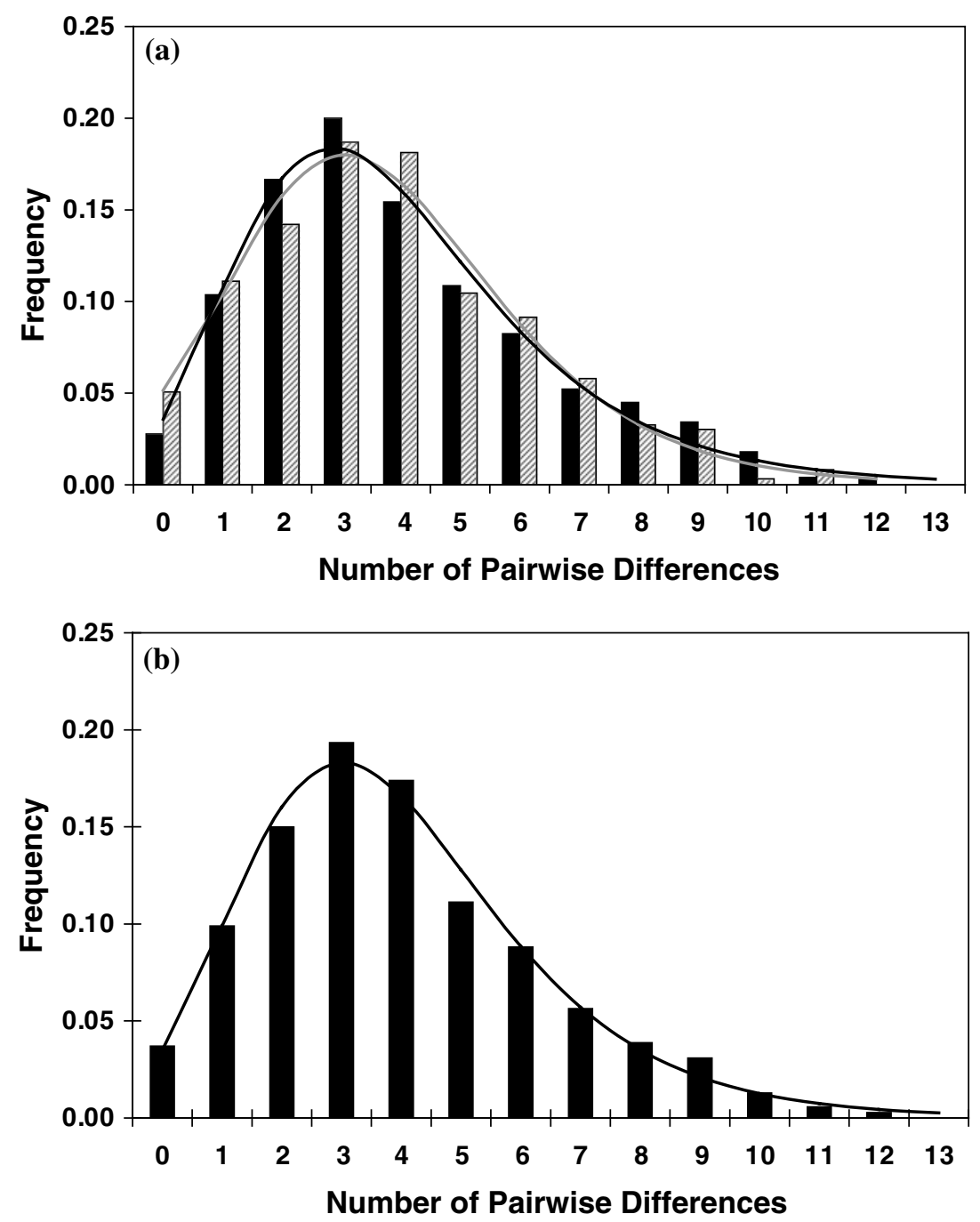

Figure 5. (a) Mismatch distributions of greater prairie chicken samples from the "original" and "expanded" ranges. Hatched and solid bars represent the observed distributions from the "original" and "expanded" ranges, respectively. Gray and black lines represent the expected distributions for the "original" $(\tau=2.863 ; P=0.730)$ and "expanded" $(\tau=2.384 ; P=0.742)$ ranges, respectively. (b) Observed and expected mismatch distributions including all greater prairie chicken samples $(\tau=2.620 ; P=0.756)$.

\section{Discussion}

Demographic and genetic evaluation of the historical range of the greater prairie chicken

Provenance data from museum collections of T. cupido provided historical information that questions the validity of the so-called following the plough hypothesis as an exclusive proposition for the range expansion of the greater prairie chicken. Analyses of MCPs indicated that the expansion of T. cupido populations into the Canadian prairies following the plough would have encompassed an estimated $550,000 \mathrm{~km}^{2}$ (Figure 2) and, if densities mirrored those of modern populations, required the establishment of at least 650,000 birds. During the relatively short period of the putative range expansion (i.e., 30-45 years of agricultural development) $T$. cupido would have spread at a rate equivalent to a radial expansion of $9.3 \mathrm{~km} /$ year while colonizing an average of $11,905 \mathrm{~km}^{2}$, i.e., an area one third larger than that of Yellowstone National Park, every year. Given that the FTP hypothesis assumes a southeast-to-northwest 
settlement pattern into the Canadian prairies (Figure 2), the linear range expansion would be considerably larger than the equivalent radial expansion, which assumes a range expansion in a circular fashion. A linear calculation based on the distance between the assumed origin of dispersal (Fargo, North Dakota, 1879) and the most distant point of the defined MCPs (Chipman, Alberta, 1921), divided by the time period of expansion (42 years), resulted in a minimum dispersal rate of $32.2 \mathrm{~km} /$ year.

The putative greater prairie chicken range expansion seems unrealistic given the relatively limited dispersal reported for this species, which indicate that the median dispersal distance for juveniles is about $1 \mathrm{~km}$ from their natal site (Bowman and Robel 1977). Furthermore, although documented migratory movements by adult females between breeding and over-wintering grounds average $10.6 \mathrm{~km}$, comparable movement by males average only $2.9 \mathrm{~km}$ (Schroeder and Braun 1993). These findings are consistent with the high lek fidelity reported for this species (Hamerstrom and Hamerstrom 1973; Bowman and Robel 1977) and the closely related lesser prairie chicken (Bouzat and Johnson 2004) and sage grouse (Dunn and Braun 1985). In our study, the estimated rate of expansion required to fit the FTP hypothesis is more comparable to expansion rates of invasive vertebrate species with high reproductive rates [e.g., the muskrat, Ondatra zibethicus, in Europe (Andow et al. 1993)] or relatively high levels of dispersal [e.g., the house finch, Carpodacus mexicanus (Mundinger and Hope 1982), and the early colonization of eastern North America by the European starling, Sturnus vulgaris (Okubo 1988)].

The estimated expansion would have required rapid population growth to support the massive recruitment necessary for the establishment of more than 650,000 birds. Estimates of relative abundance over the assumed expansion period fit an exponential growth model with a constant per capita rate of increase of $8.9 \%$ per year over the 46-year period considered. Although greater prairie chickens have a relatively large mean clutch size (12 eggs) that could support a high population growth rate, nest success in established populations is only $46-50 \%$, survival of fertile eggs can be as low as $20 \%$, and early brood mortality can range between $45-85 \%$ (data compiled in Johns- gard 1983, and Wisdom and Mills 1997). Given the limited dispersal and establishment capabilities witnessed from modern greater prairie chicken populations, the possibility of this species expanding as quickly as postulated by the FTP hypothesis seems unlikely. However, if the expansion never occurred one would have to explain the apparent expansion pattern reflected by the provenance data from the museum collections (Figure 2). Considering that the apparent expansion is actually based on a very limited number of records increasing the area of each MCP (i.e., by the addition of only $1-5$ museum specimens), we believe this pattern reflects the progressive sampling of prairie areas by early naturalists during the hypothesized period of expansion. This idea is supported by a similar expansion pattern detected in a group of 21 grassland birds commonly thought to be indigenous to the Canadian prairies (based on 1867 records; data not shown).

Admittedly, the demographic approach presented here provided only overall estimates of the area and rate of population growth that would be associated with a putative FTP expansion. The precision of these estimates is, however, limited by the assumptions of equally suitable habitat within MCPs and population density. We therefore looked for another independent line of evidence (i.e., genetic analysis) to further assess the putative expansion.

A rapid demographic expansion of greater prairie chickens following the plough would most likely have imprinted a genetic signal at the population level. Under the assumption of the FTP hypothesis, the putative expansion would have occurred as a stepwise progression from a limited region of the greater prairie chicken's original range. Thus, the "expanded" population would have retained less genetic diversity than that present throughout the range of the "original" population (see García-Ramos and Rodríguez 2002; Hutchison 2003). On the contrary, our results did not reveal higher levels of genetic diversity within core populations (Table 1). In fact, similar levels of within-group diversity were observed even when considering samples from the westernmost region of the putative expanded range (i.e., Alberta and Saskatchewan). A genetic signal of decreased diversity, if present, would be more likely to be found in these samples. One 
could argue that a rapid expansion from a limited range of a species' distribution may not always result in decreased genetic diversity, since population expansions do not necessarily involve a few founders and migration events following the expansion can rapidly increase genetic variation (see Hansson et al. 2000). However, these processes would result in low levels of genetic differentiation between source and founded populations. In our case, the genetic survey of $T$. cupido mtDNA haplotypes revealed significant levels of genetic differentiation between samples from the "original" and "expanded" ranges (detected by the AMOVA), and the presence of multiple haplotypes unique to each range (Figure 4). These results are consistent with the idea that these populations have been relatively isolated for significant evolutionary time periods, and were not the result of a massive expansion from the "original" greater prairie chicken range during agricultural development.

The genetic analysis of DNA samples from historical populations also provided an opportunity to evaluate past demographic events associated with the evolutionary history of $T$. cupido. Historical demographic events, such as episodes of population growth and decline, leave characteristic genetic signatures in mtDNA mismatch distributions (Rogers and Harpending 1992). Although DNA mismatch distributions may be misleading about recent demographic processes (see Lavery et al. 1996), they have proved useful for evaluating episodes of exponential population growth over evolutionary times; e.g., when a species is expanding its geographic range for the first time (Slatkin and Hudson 1991).

The observed mismatch distribution for the greater prairie chicken (i.e., including samples from both "original" and "expanded" ranges) provided a significant fit to a species-wide expansion occurring about $9000 \mathrm{ybp}$, following the recession of the Wisconsonian glaciations. The $T$. cupido expansion matches the recently documented vegetation history of late-Quaternary biomes in boreal and eastern North America reported by Williams et al. (2004). The reconstruction of biome distributions over the past 21,000 years (using fossil pollen evidence) revealed the emergence of the Canadian prairies/steppes at about $10,000 \mathrm{ybp}$ with a range and abundance maximum occurring between $8000-5000$ years ago
(Williams et al. 2004). Interestingly, $\tau$ values from mismatch distributions for the "expanded" population pointed to a time of genetic coalescence between 8000 and 5500 years ago (depending on the mutation rate used).

Although mtDNA mismatch distributions have been extensively used to estimate demographic parameters of past population expansions, recent studies have cautioned their use for inferring demographic history (e.g., Charlesworth et al. 2003; Ballard and Whitlock 2004). Concerns include errors in the estimation of gene genealogies from a single or multiple linked genes in the mitochondria, potential recombination, and the assumption that mtDNA evolves as a neutral marker. In our study, using the Tajima's (1989) test, we were not able to reject the hypothesis of selective neutrality (Tajima's $D=-1.22$; $P=0.110)$. Although we cannot completely eliminate the hypothesis of a potential selective sweep at the mtDNA level, a mismatch distribution analysis of a subset of 17 nuclear DNA sequences from intron 2 of the $\beta$-actin gene $(737 \mathrm{bp}$; GenBank accession numbers: AY855213-AY855225) provided similar results to those reported for the mtDNA control region, consistent with a postPleistocene expansion of the species $(\tau=3.729$; 95\% CI $=1.641-6.251 ; P<0.766)$.

In this study, we demonstrated the value of both provenance and genetic data from museum specimens and contemporary populations for evaluating a species' historical range. Our demographic results provide evidence questioning the validity of the FTP hypothesis as an exclusive proposition for the greater prairie chicken population expansion, suggesting that the Canadian prairies may have been part of the native range of this species. The analysis of genetic diversity within and between "original" and "expanded" ranges was consistent with this idea, indicating that these populations have been relatively isolated for long evolutionary time periods and thus, were not the result of a recent demographic expansion. Furthermore, DNA mismatch distributions indicated that a postPleistocene population expansion of greater prairie chickens was likely associated with the retraction of glaciers during the last Ice Age, and the emergence of prairies in the central Canadian plains. A postPleistocene expansion of $T$. cupido range is also supported by the current distribution of the sharp tailed grouse ( $T$. phasianellus), a sister species in the 
prairie grouse complex, which primarily inhabits the aspen parkland/grassland ecotone adjacent to the mixed-prairies of central United States and Canada. Hubbard (1973) hypothesized that contemporary species within Tympanuchus, including $T$. cupido and $T$. phasianellus, evolved through a recent vicariance split of a widely distributed ancestral grouse species, an idea consistent with recent phylogenetic characterizations of the prairie grouse complex (Dimcheff et al. 2002; Drovetski and Ronquist 2003).

One could argue that the apparent range expansion that may be inferred from museum collections of greater prairie chickens questions the reliability of museum specimens to characterize historical changes in species range. We suggest that special caution should be taken when evaluating putative range expansions during the early periods of European settlement; i.e., at the time when the first major museum collections were being established. For example, bird collections from the Field Museum of Natural History (Chicago), the Peabody Museum of Vertebrate Zoology (Yale), the University of Michigan Museum of Zoology (Ann Arbor), the Canadian Museum of Nature (Ottawa), and the Provincial Museum of Alberta (Edmonton) contained no complete record of any bird specimen from the focal grassland areas of North Dakota, Manitoba, Saskatchewan and Alberta prior to 1873 , very few specimens collected during 1873-1889 (83 records), a drastic increase in the number of specimens collected between 1890 and 1899 (1329 records), with the vast majority of specimens taken after 1900 (data based on a total of 7748 specimens collected prior to 1930). The apparent pattern of greater prairie chicken expansion most likely reflects the progressive collection of museum specimens in areas previously uninhabited or unexplored by European settlers. An apparent pattern of expansion to the northwest detected in a group of grassland bird species indigenous to the Canadian prairies is consistent with this idea (Bouzat and Ross, in preparation).

\section{Implications for conservation}

Conservation and management strategies for declining populations are highly dependent on a proper evaluation of the historical distribution of the species under consideration. Understanding the degree to which a species has declined, both demographically and spatially, is crucial for the protection of relict populations or, in some cases, the planning of re-introduction programs for re-establishment of currently extinct populations.

The greater prairie chicken represents a clear example of how common perceptions regarding the historical range of a species may have direct consequences on the conservation status and management strategies for a declining species. Under the FTP hypothesis, T. cupido was thought to have expanded its range as a result of agricultural development to the west, and then declined due to over-hunting and habitat loss. In 1993 the Committee on the Status of Endangered Wildlife in Canada (COSEWIC) endorsed the Recovery of Nationally Endangered Wildlife report (Hjertaas et al. 1993), which concluded that the now extirpated greater prairie chicken expanded its range into the Canadian prairies as a result of European settlement. Thus, COSEWIC classified the species as "non-native extirpated;" consequently, all recovery efforts in Canada were abandoned. Similarly, greater prairie chicken populations remaining in the so-called "expanded" region of some USA states (e.g., Minnesota and North Dakota), although listed as species "of special concern" (MN; Coffin and Pfannmuller 1988) or "threatened" (ND; Kobriger 1999), are not protected as native species that have suffered significant population declines. In fact, the Minnesota Department of Natural Resources has issued hunting permits for this species over the past 3 years (DNR-Minnesota 2005), even though statewide population declines and prairie habitat fragmentation over the past century (Svedarsky et al. 1999b) could qualify the species as "threatened" using IUCN criteria (IUCN 2001).

The present study questions the validity of the FTP hypothesis and suggests that greater prairie chickens were most likely long-term residents of the northern prairies, extending from central Minnesota, USA to Alberta, Canada. Consequently, the current status of the greater prairie chicken should be re-evaluated within all areas where this species may occur, but is now considered non-native. As it now seems apparent that the historical range of this species includes vast areas originally thought to be part of an expanded range, the global decline of the greater prairie chicken over the past 150 years is undoubtedly 
more significant than previously thought. In light of our conclusions, we stress the value of museum collections as stores of ecological and genetic information useful in determining species' historical ranges and past demographic events, both fundamental aspects for the conservation of natural populations.

\section{Acknowledgements}

This work was supported by Department of Biological Sciences at Bowling Green State University, the Brandon University Research Committee, and the H. Stewart Perdue Award. We thank Christopher Tracey for technical assistance on GIS mapping, and Karen V. Root, Scott Mills, Ken N. Paige and three anonymous reviewers for helpful comments on the manuscript. The following museums provided access for specimen sampling: American Museum of Natural History (New York, NY), B.J. Hales Museum of Natural History (Brandon, MB), Canadian Museum of Nature (Ottawa, ON), Field Museum of Natural History (Chicago, IL), Manitoba Museum of Man and Nature (Winnipeg, MB), Museum of Vertebrate Zoology (Berkeley, CA), National Museum of Natural History (Washington, DC), Royal Ontario Museum (Toronto, ON), Royal Saskatchewan Museum (Regina, SK), and the U. of Alberta Museum of Zoology (Edmonton, AB). The following institutions provided T. cupido provenance data: Academy of Natural Sciences (Philadelphia, PA), Delaware Museum of Natural History (Wilmington, DE), Denver Museum of Nature and Science (CO), Dickey Collection UCLA (Los Angeles, CA), Florida Museum of Natural History (Gainesville, FL), Milwaukee Public Museum (Milwaukee, WI), Museum of Comparative Zoology at Harvard (Cambridge, MA), New York State Museum (Albany, NY), Ohio State University Museum of Biological Diversity (Columbus, OH), Peabody Museum at Yale (New Haven, CT), Provincial Museum of Alberta (Edmonton, AB), San Diego Natural History Museum (San Diego, CA), Sam Noble Oklahoma Museum of Natural History (Norman, OK), The Natural History Museum (London, UK), U. of Michigan Museum of Zoology (Ann Arbor, MI), U. of Nevada (Reno, NV), and Western Foundation of Vertebrate Zoology (Camarillo, CA).

\section{References}

Andow D, Kareiva P, Levin SA, Okubo A (1993) Spread of invading organisms: patterns of spread. In: Evolution of Insect Pests: The Pattern of Variations (ed. Kim KC), pp. 219-242. Wiley, New York.

Applegate RD, Horak GJ (1999) Status and management of the greater prairie chicken in Kansas. In: The Greater Prairie Chicken: A National Look (eds. Svedarsky WD et al.), pp. 113-121. Minnesota Agricultural Experiment Station publication 99-1999, University of Minnesota, Saint Paul, Minnesota.

Arndt AD, Van Neer W, Hellemans B, Robben J, Volckaert F, Waelkens M (2003) Roman trade relationships at Sagalassos (Turkey) elucidated by ancient DNA from fish remains. J. Archaeol. Sci., 30, 1095-1105.

Audubon MR (1960) Audubon and His Journals, Dover Publications, New York.

Avise JC, Walker D (1998) Pleistocene phylogeographic effects on avian populations and the speciation process. Proc. Royal Soc. London Ser. B-Biol. Sci., 265, 457-463.

Ballard JWO, Whitlock MC (2004) The incomplete natural history of mitochondria. Mol. Ecol., 13, 729-744.

Bouzat JL (2001) The importance of control populations for the identification and management of genetic diversity. Genetica, 110, 109-115.

Bouzat JL, Lewin HA, Paige KN (1998) The ghost of genetic diversity past: historical DNA analysis of the Greater Prairie Chicken. Am. Nat., 152, 1-6.

Bouzat JL, Johnson K (2004) Genetic structure among closelyspaced leks in a peripheral population of lesser prairiechickens. Mol. Ecol., 13, 499-505.

Bowman TJ, Robel RJ (1977) Brood break-up, dispersal, mobility, and mortality of juvenile prairie chickens. J. Wildlife Manage., 41, 27-34.

Charlesworth B, Charlesworth D, Barton NH (2003) The effects of genetic and geographic structure on neutral variation. Ann. Rev. Ecol., Evol. Syst., 34, 99-125.

Coffin B, Pfannmuller L (1988) Minnesota's Endangered Flora and Fauna, University of Minnesota Press, Minneapolis.

Collins SL (2001) Long-term research and the dynamics of bird populations and communities. Auk, 118, 583-588.

Cooke W (1888) Report on Bird Migration in the Mississippi Valley in the Years 1884 and 1885. Department of Agriculture Ornithology Bulletin 2, U.S. Government Printing Office, Washington, D.C.

Coues E (1874) Birds of the Northwest, U.S. Government Print Office, Washington, D.C.

Dimcheff DE, Drovetski SV, Mindell DP (2002) Phylogeny of Tetraoninae and other galliform birds using mitochondrial 12S and ND2 genes. Mol. Phylogenet. Evol., 24, 203-215.

DNR-Minnesota (2005) 2005 Minnesota Hunting Regulations, St. Paul, Minnesota.

Douglas D (1829) Observations on some species of the genera Tetrao and Ortyx, natives of North America, with descriptions of four new species of the former, and two of the latter genus. Trans. Linn. Soc. London, 16, 133-149.

Drovetski SV (2002) Molecular phylogeny of grouse: individual and combined performance of W-linked, autosomal, and mitochondrial loci. Syst. Biol., 51, 930-945. 
Drovetski SV, Ronquist F (2003) Plio-Pleistocene climatic oscilations, Holarctic biogeography and speciation in an avian subfamily. J. Biogeogr., 30, 1173-1181.

Dunn PO, Braun CE (1985) Natal dispersal and lek fidelity of sage grouse. Auk, 102, 621-627.

García-Ramos G, Rodríguez D (2002) Evolutionary speed of species invasions. Evolution, 56, 661-668.

Hamerstrom F, Hamerstrom F (1973). The prairie chicken in Wisconsin: highlights of a 22-year study of counts, behavior, movements, turnover and habitat. Technical Bulletin 64, Department of Natural Resources, Madison, Wisconsin.

Hansson B, Bensch S, Hasselquist D, Lillandt BG, Wennerberg L, Von Schantz T (2000) Increase of genetic variation over time in a recently founded population of great red warblers (Acrocephalus arundinaceus) revealed by microsatellites and DNA fingerprinting. Mol. Ecol., 9, 1529-1538.

Hind HY (1860) Narrative of the Canadian Red River Exploring Expedition of 1857; and of the Assinniboine and Saskatchewan Exploring Expedition of 1858. Longman, Green, Longman and Roberts, London.

Hjertaas D, Brechtel S, Jones R, Edwards R, Schroeder C (1993) National Recovery Plan for the Greater PrairieChicken. Report No. 5, Recovery of Nationally Endangered Wildlife Committee, Ottawa.

Hooge PN, Eichenlaub B (2000) Animal Movement Extension to Arcview, Alaska Science Center - Biological Science Office, U.S. Geological Survey, Anchorage, AK.

Houston CS (2002) Spread and disappearance of the greater prairie-chicken, Tympanuchus cupido, on the Canadian prairies and adjacent areas. Can. Field-Nat., 116, 1-21.

Hubbard JP (1973) Avian evolution in the arid-lands of North America. Living Bird, 12, 155-196.

Hutchison DW (2003) Testing the central/peripheral model: analysis of microsatellite variability in the eastern collared lizard. Am. Midland Nat., 149, 148-162.

IUCN (2001) IUCN Red List Categories, v. 3. 1, International Union for the Conservation of Nature (IUCN), Gland, Switzerland.

Johnsgard PA (1983) The Grouse of the World, University of Nebraska Press, Lincoln.

Johnson JA, Dunn PO (2006) Low genetic variation in the Heath Hen prior to extinction and implications for the conservation of prairie-chicken populations. Conserv. Genet. (in press).

Johnson JA, Toepfer JE, Dunn PO (2003) Contrasting patterns of mitochondrial and microsatellite population structure in fragmented populations of greater prairie-chickens. Mol. Ecol., 12, 3335-3348.

Johnson JA, Bellinger MR, Toepfer JE, Dunn PO (2004) Temporal changes in allele frequencies and low effective population size in greater prairie-chickens. Mol. Ecol., 13, 2617-2630.

King WR (1866) The Sportsman and Naturalist in Canada, Hurst and Blackett, London.

Kirsch LM, Kruse AD (1972) Prairie fires and wildlife. pp. 289303. Annual Tall Timbers Fire Ecology Conference. Northern Prairie Wildlife Research Center, Bureau of Sport Fisheries and Wildlife.

Kobriger JD (1999) Status and management of the greater prairie chicken in North Dakota. In The Greater Prairie Chicken: A National Look (eds. Svedarsky WD et al.), pp. 63-74. Min- nesota Agricultural Experiment Station publication 99-1999, University of Minnesota, Saint Paul, Minnesota.

Kumar S, Tamura K, Jakobsen IB, Nei M (2001) MEGA2: molecular evolutionary genetics analysis software. Bioinformatics, 17, 1244-1245.

Lambert DM, Ritchie PA, Millar CD, Holland B, Drummond AJ, Baroni C (2002) Rates of evolution in ancient DNA from Adélie penguins. Science, 295, 2270-2273.

Lavery S, Moritz C, Fielder DR (1996) Genetic patterns suggest exponential population growth in a declining species. Mol. Biol. Evol., 12, 1106-1113.

Lessa EP, Cook JA, Patton JL (2003) Genetic footprints of demographic expansion in North America, but not Amazonia, during the Late Quaternary. Proc. Natl. Acad. Sci. USA, 100, 10331-10334.

Lieberman BS (2000) Palaeobiogeography: Using Fossils to Study Global Change, Plate Tectonics, and Evolution, Plenum Press/Kluwer Academic Publishers, New York.

Lucchini V, Hoglund J, Klaus S, Swenson J, Randi E (2001) Historical biogeography and a mitochondrial DNA phylogeny of grouse and ptarmigan. Mol. Phylogenet. Evol., 20, 149-162.

Mundinger PC, Hope S (1982) Expansion of the winter range of the house finch: 1947-1979. Am. Birds, 36, 347-353.

Nei M, Kumar S (2000) Molecular Evolution and Phylogenetics, Oxford University Press, New York, NY, USA.

Okubo A (1988) Diffusion-type models for avian range expansion In: Acta XIX Congress Internationalis Ornithologici (ed. Ouellet H), pp. 1038-1049. National Museum of Natural Sciences, University of Ottawa Press, Ottawa.

Pergams ORW, Barnes WM, Nyberg D (2003) Mammalian microevolution: rapid change in mouse mitochondrial DNA. Nature, 423, 397.

Posada D, Crandall KA (1998) MODELTEST: testing the model of DNA substitution. Bioinformatics, 14, 817-818.

Quinn TW (1992) The genetic legacy of Mother Goose: phylogeographic patterns of lesser snow goose Chen caerulescens caerulescens maternal lineages. Mol. Ecol., 1, 105-117.

Quinn TW, Wilson AC (1993) Sequence evolution in and around the control region in birds. J. Mol. Evol., 37, 417-425.

Roberts TS (1932) The Birds of Minnesota, University of Minnesota Press, Minneapolis.

Rogers AR (1992) Error introduced by the infinite-sites model. Mol. Biol. Evol., 9, 1181-1184.

Rogers AR (1995) Genetic-evidence for a Pleistocene population explosion. Evolution, 49, 608-615.

Rogers AR, Harpending H (1992) Population-growth makes waves in the distribution of pairwise genetic-differences. Mol. Biol. Evol., 9, 552-569.

Rowe KC, Heske EJ, Brown PW, Paige KN (2004) Surviving the ice: Northern refugia and postglacial colonization. Proc. Natl. Acad. Sci. USA, 101, 10355-10359.

Rozas J, Rozas R (1999) DnaSP version 3: an integrated program for molecular population genetics and molecular evolution analysis. Bioinformatics, 15, 174-175.

Sambrook J, Fritsch EF, Maniatis T (1989) Molecular Cloning, Cold Spring Harbor Laboratory Press, New York.

Schneider S, Excoffier L (1999) Estimation of past demographic parameters from the distribution of pairwise differences when the mutation rates very among sites: application to human mitochondrial DNA. Genetics, 152, 1079-1089. 
Schneider S, Roessli D, Excoffier L (2000) Arlequin, Version 2.000: a software for population genetics data analysis Genetics and Biometry Laboratory, University of Geneva, Switzerland.

Schroeder MA, Braun CE (1993) Partial migration in a population of greater prairie-chickens in Northeastern Colorado. Auk, 110, 21-28.

Shaffer HB, Fisher RN, Davidson C (1998) The role of natural history collections in documenting species declines. Trends Ecol. Evol., 13, 27-30.

Slatkin M, Hudson RR (1991) Pairwise comparisons of mitochondrial DNA sequences in stable and exponentially growing populations. Genetics, 129, 555-562.

Svedarsky WD, Hier RH, Silvy NJ, eds. (1999a) The greater prairie chicken: a national look. Minnesota Agricultural Experimentation Station publication 99-1999, University of Minnesota, St. Paul, Minnesota.

Svedarsky WD, Wolfe TJ, Toepfer JE (1999b) Status and management of the greater prairie chicken in Minnesota. In: The Greater Prairie Chicken: A National Look (eds. Svedarsky WD et al.), pp. 25-38. Minnesota Agricultural
Experiment Station publication 99-1999, University of Minnesota, Saint Paul, Minnesota.

Tajima F (1989) Statistical method for testing the neutral mutation hypothesis by DNA polymorphism. Genetics, 123, 585-595.

Thompson JD, Gibson TJ, Plewniak F, Jeanmougin F, Higgins DG (1997) The ClustalX windows interface: flexible strategies for multiple sequence alignment aided by quality analysis tools. Nucl. Acids Res., 24, 4876-4882.

Trippe TM (1871) Some differences between western and eastern birds. Am. Nat., 5, 632-636.

Toepfer JE (2003) Prairie Chickens and Grasslands: 2000 and Beyond, Society of Tympanuchus Cupido Pinnatus Ltd., Elm Grove, Wisconsin.

Williams JW, Shuman BN, Webb T, Bartlein PJ, Leduc PL (2004) Late quaternary vegetation dynamics in North America: scaling from taxa to biomes. Ecol. Monogr., 74, 309-334.

Wisdom MJ, Mills LS (1997) Sensitivity analysis to guide population recovery: prairie-chickens as an example. J. Wildlife Manage., 61, 302-312. 